\title{
Editorials
}

\section{Is It Time to Say Good Bye to Blow-By?}

While it has been clearly demonstrated that spontaneously breathing children of all ages with bronchospasm respond well to nebulized bronchodilators, only a small proportion of aerosolized drug reaches the lungs. ${ }^{1-9}$ In addition, the combination of a small airway diameter, a rapid breathing pattern, and poor tolerance to the treatment has made delivery of nebulized medications to the airway of pediatric patients very challenging.

The face mask is one of the most frequently prescribed aerosol devices for the administration of bronchodilators to children, in a variety of clinical settings. Their advantage is the little to no cooperation required from the child. Nevertheless, the presence of a tight seal on the patient's face has been considered a critical element to improve aerosol delivery. Amirav et al have found that the absence of this seal between the mask and the patient's face results in a decrease in the amount of medication available for inhalation. ${ }^{10}$ Children, especially those who are combative and crying, often resist or reject the presence of an aerosol mask on their faces; thus, the efficacy of aerosol therapy administered to agitated children may be negligible. ${ }^{11}$

In order to avoid the poor tolerance children have to the tightly applied aerosol mask, clinicians often place the mask away from the child's face, a technique also known as "blow by." However, experimental data have revealed that the greater the distance between the aerosol mask and the patient's face, the lower the amount of inhaled drug mass. ${ }^{2,12}$ After conducting an evaluation of 3 different mask designs at 3 different distances from a mannequin face, we reported that mask design affected nebulized albuterol delivery and that inhaled drug mass was significantly reduced as the aerosol mask was moved away from the face. ${ }^{12}$

We had also previously reported that nebulized albuterol delivery, measured as inhaled drug mass, was significantly reduced as the aerosol mask or T-piece ${ }^{13}$ was moved away from the face ${ }^{12}$ in a pediatric lung model of spontaneous breathing. An accompanying editorial titled "ByeBye, Blow-By" called for a recommendation to discourage clinicians from using the blow-by technique, based on available data. ${ }^{14}$

To address some of the challenges encountered during the administration of nebulized medications to spontaneously breathing children, research has focused on several areas. These include the evaluation of newer interfaces and different types of aerosol systems, and the impact of administering the aerosol away from the child's face.

For example, evaluation in vitro of different aerosol masks has shown that mask design impacts the amount of nebulized medication delivered to the airway of pediatric patients. The fish mask in combination with the Pari LC Plus nebulizer has been associated with almost a 50-65\% higher inhaled drug mass, and the lowest eye and facial aerosol depositions, when compared to other combinations of masks and nebulizers. ${ }^{15,16}$ Nevertheless, the majority of the changes to pediatric aerosol masks have been made to those attached to spacers for delivery of medications through pressurized metered-dose inhalers, and the conventional pediatric aerosol masks used with jet nebulizers are typically a smaller version of the masks used with adults, with a considerably large volume of potential dead space and relatively large side holes.

In regards to evaluation in vitro of a T-piece as an alternative to the aerosol mask, even if used as blow-by, we found that at 1 and $2 \mathrm{~cm}$ away from a mannequin face the nebulized albuterol inhaled drug mass was substantially higher than that obtained with a conventional aerosol mask at 0,1 , and $2 \mathrm{~cm}$ away from the face. ${ }^{13}$ These results point to the importance of the physical design of the aerosol device, as well as the importance of the type of nebulizer system, even when distance from the face is not considered as a variable.

See the Original Study on Page 2004

In this issue of ResPiratory CARE, Mansour and Smaldone conducted an evaluation of blow-by in a pediatric model as potential therapy for uncooperative children. ${ }^{17}$ Three commercially available nebulizer/compressor/face mask systems (Pari Sprint, Respironics Sidestream, and Salter 8900) were used to nebulize budesonide at 0,2 , and $4 \mathrm{~cm}$ from the face. Inhaled drug mass and the deposition on face, eyes, and mask were measured.

They found that at $0 \mathrm{~cm}$ the inhaled drug mass for the Pari system was 35\% higher than the Salter, and $79 \%$ higher than the Respironics Sidestream. If we compare Pari's performance to the systems we have evaluated, the inhaled mass obtained with the Pari system was $60 \%$ and $30 \%$ higher than the Hudson nebulizer plus standard aerosol mask, and Hudson nebulizer plus fish mask, respec- 
tively. ${ }^{12}$ These results support the fact that successful administration of a nebulized drug is a function of the nebulizer system as a whole, and not its separate components. An optimally designed mask and a high performance nebulizer system should result in a higher deposition of aerosol in the lower airways and better clinical outcomes.

When evaluated at $4 \mathrm{~cm}$ away from the mannequin face, the inhaled mass decreased more than $60 \%$ for both the Pari and the Salter, and almost $90 \%$ for the Respironics system. However, the inhaled mass percentages were even twice as high as the inhaled mass we obtained evaluating a conventional mask and a Hudson nebulizer, and only $20 \%$ lower than the fish mask plus Hudson system at only $2 \mathrm{~cm}$ distance from the face. ${ }^{12}$ Based on these results we can see the importance of using a good performance system when a clinician selects blow-by as the best and only strategy to deliver the medication to the uncooperative child.

The time to complete the treatment was significantly longer with the Pari $(7.7 \mathrm{~min})$ versus the Salter $(5.3 \mathrm{~min})$ and the Respironics (4.0 min), as a function of a lower flow rate used to power the nebulizer. This factor is hard to ignore. Let's do the math. If an uncooperative child can only stand half of the time it takes to deliver the treatment with the most efficient system, it brings us back to square one, which is that we have delivered only half of the intended dose. And, of course, this is assuming the distance between the child's face and the mask did not vary substantially during the treatment.

I could not agree more with the authors when suggesting that the selection of a high performance nebulizer system may be useful for use in blow-by, since it may compensate for the effect of increasing distances from the face. I would argue that this nebulizer system should be the first option for spontaneously breathing children, regardless of how cooperative they appear to be. However, two issues need to be given special consideration. First, use of a high-performance system comes at a cost. Affordability of a generic versus a brand name medication is always an issue in clinical medicine. It is also a reality often experienced by respiratory departments that see evidence-based medicine practices as an expensive proposition. Clinicians often feel the frustration of not offering the best possible care when they know that a therapy or product with a higher tag price works better than the inexpensive day-today product used by their institution. Administrators should look at the results of this study as an opportunity to conduct a cost-effectiveness evaluation. Unless the use of these very efficient systems is supported by better clinical outcomes, the conclusions will have the inevitable limitations of a bench model. The second issue is how applicable these results are. When speaking of uncooperative children, one can only picture the child's face as a moving target. The therapist holding the mask will be the one chasing that target from what may appear as "miles away." The mannequin's face is not exactly the best example of an uncooperative child, but is a good option we researchers have to suggest changes in therapy. The 2 or 4 centimeters distance between the aerosol mask and the child's face becomes truly immeasurable and realistically much greater than those distances we all have referenced in previous studies in vitro.

Looking back at the editorial by Dr Rubin, "Bye-Bye, Blow By," 14 the results of the study by Mansour and Smaldone invite an editorial I could title like the song by Justin Bieber my daughter loves so much: "Never Say Never." However, this is my final thought: if you routinely use a very efficient nebulizer system for uncooperative children such as those presented in this study, please don't hesitate to use them. The only caveat: if you can afford coaching the child and can place the mask with a good and tight seal, don't you ever use blow-by.

Ruben D Restrepo MD RRT FAARC Department of Respiratory Care The University of Texas Health Sciences Center at San Antonio San Antonio, Texas

\section{REFERENCES}

1. Everard ML, Clark AR, Milner AD. Drug delivery from holding chambers with attached facemask. Arch Dis Child 1992;67(5):580585 .

2. Everard ML, Clark AR, Milner AD. Drug delivery from jet nebulisers. Arch Dis Child 1992;67(5):586-591.

3. Rubin BK, Fink JB. Aerosol therapy for children. Respir Care Clin N Am 2000;7(2):175-213.

4. Salmon B, Wilson NM, Silverman M. How much aerosol reaches the lungs of wheezy infants and toddlers? Arch Dis Child 1990;65(4): 401-403.

5. Newhouse MT. Pulmonary drug targeting with aerosols: principles and clinical applications in adults and children. Am J Asthma Allergy Pediatr 1993;7(1):23-25.

6. Chua HL, Collis GG, Newbury AM, Chan K, Bower GD, Sly PD, LeSouef PN. The influence of age on aerosol deposition in children with cystic fibrosis. Eur Respir J 1994;7(12):2185-2291.

7. Newhouse MT, Dolovich M. Aerosol therapy in children. In: Chernick V, Mellins RB, editors. Basic mechanisms of pediatric respira-

Dr Restrepo has disclosed relationships with Oridion and Teleflex.

Correspondence: Ruben D Restrepo MD RRT FAARC, Department of Respiratory Care, The University of Texas Health Science Center at San Antonio, MSC 6248, San Antonio TX 78229. E-mail: restrepor@ uthscsa.edu.

DOI: $10.4187 /$ respcare.02158 


\section{Is It Time to Say Good Bye to Blow-By?}

tory disease: cellular and integrative. Philadelphia: Decker; 1991: 409-417.

8. Fok TF, Monkman S, Dolovich M, Gray S, Coates G, Paes B. Efficiency of aerosol medication delivery from a metered dose inhaler versus jet nebulizer in infants with bronchopulmonary dysplasia. Pediatr Pulmonol 1996;21(5):301-309.

9. Anhoj J, Thorsson L, Bisgaard H. Lung deposition of inhaled drug increases with age. Am J Respir Crit Care Med 2000;162(5):1819-1822.

10. Amirav I, Newhouse MT. Aerosol therapy with valved holding chambers in young children: importance of the facemask seal. Pediatrics 2001;108(2):389-394.

11. Iles R, Lister P, Edmunds AT. Crying significantly reduces absorption of aerosolized drug in infants. Arch Dis Child 1999;81(2):163165 .
12. Lin HL, Restrepo RD, Gardenhire DS, Rau JL. Effect of face mask design on inhaled mass of nebulized albuterol, using a pediatric breathing model. Respir Care 2007;52(8):1021-1026.

13. Restrepo RD, Dickson SK, Rau JL, Gardenhire DS. An investigation of nebulized bronchodilator delivery using a pediatric lung model of spontaneous breathing. Respir Care 2006;51(1):56-61.

14. Rubin BK. Bye-bye, blow by. Respir Care 2007;52(8):981.

15. Sangwan S, Gurses BK, Smaldone GC. Facemasks and facial deposition of aerosols. Pediatr Pulmonol 2004;37(5):447-452.

16. Smaldone GC, Berg E, Nikander K. Variation in pediatric aerosol delivery: importance of facemask. J Aerosol Med 2005;18(3):354-363.

17. Mansour MM, Smaldone GC. Blow-by as potential therapy for uncooperative children: an in-vitro study. Respir Care 2012;57(12): 2004-2011. 